\title{
Exploration of Professional Cognitive Education in Agricultural Colleges Specific to the Characteristics of "Post-95s" Freshman
}

\author{
Zhaojun TAN ${ }^{1,2}$, Li LI*1, ${ }^{*}$, Dongqing BAI ${ }^{1,2}$ and Xiuting QIAO ${ }^{1,2}$ \\ 1. Marine Production Institute of Tianjin Agricultural University, Tianjin Agricultural University 300384 \\ 2. National-level Experiment Teaching Demonstration Center for Aquatic Ecosystem and Cultivation, Tianjin Agricultural \\ University 300384
}

\begin{abstract}
As the present growth environment has been largely improved, the "post-95s" freshmen show different characteristics in psychology and behaviors; According to the characteristics of the "post-95s" freshmen, this article has briefly discussed the professional cognitive education of city agricultural colleges and provided corresponding suggestions and countermeasures. In combination with the school-running characteristics of city agricultural colleges, the education and teaching mode and methods have been appropriately adjusted, which can exert a positive and profound influence on colleges' own development and agricultural talent cultivation.
\end{abstract}

Keywords-Agricultural colleges; Characteristics of "post-95s" freshmen; Professional cognitive education

\section{INTRODUCTION}

Professional cognitive education is an inevitable phase for freshmen to march towards colleges, and is also an important platform for freshmen to have an initial understanding about the major learned thereby, and is also an important turning point for freshmen to convert from the passive education in middle schools to the autonomous learning in colleges. Specific to students' thought and behavior characteristics and in combination with the school-running characteristics of city agricultural colleges, it appropriately adjusted the education and teaching mode and methods, and can exert a positive and profound influence on colleges' own development and agricultural talent cultivation.

\section{CHARACTERISTICS OF "POST-95S" FRESHMEN} MAJORING IN AGRICULTURE RELATED SPECIALTIES

At the end of 2017, the last batch of children after 90s became adults, meaning that the entire college students are almost composed of the generation "after 95s". However, they were born at the end of the 20th century when the reform and opening up policy was carrying out, and then grew up in a peaceful and free era; they are the generation growing up along with the fast development course of economic construction, science and technology in our country, and they are different from previous young people in psychology and behaviors.

\section{A. Psychological Characteristics}

\section{1) Coexistence of Freedom and Dependence}

On one hand, the generation "after 95s" was born in an era of highly prosperous culture, and the living condition for most families can be slightly improved than before, and partial children's living conditions can be quite superior; meanwhile, under the strong impact of western culture and value concept, they can speak boldly, with divergent thinking and rich creativity; they celebrate romantic, free and easy living mode as well as free and open ideological concepts[1], and they are reluctant to be restricted by regulations and rules; in the investigation about employment intention, most students are looking forward to having elastic freelance work or have the intention of entrepreneurship. According to the information provided by the Tianjin Agricultural University Innovation and Entrepreneurship Center: The quantity of students applying for participating in Tianjin Agricultural University Entrepreneurship Service Provider Alliance has presented a trend of increase; in 2016, the alliance not only successfully held "Zhuangyuan Cup", " Challenge Cup" innovation and entrepreneurship project competitions, but also signed cooperation practice base with Zhongbei Town, Unionpay, etc., and then in 2017, it newly increased 5 enterprise and public institutions. On the other hand, firstly, as the main audiences of "Internet Plus", since they are not good at making contact with others in real life, the generation "after 95s" can rely more on searching for solutions in the virtual network when faced with difficulties,; secondly, the overproduction of most parents for their children has caused the failure for students to independently make decisions in the face of major problems, and they will place hope on others' strength and decisions, finally, the generation "after 95s" mostly grows up under the environment of being well cared, and will show timidity and fragility in the face of problems, with bad capacity for bearing responsibilities and undertaking pressures, and will easily pass the buck in the face of problems. 


\section{2) Coexistence of Self-esteem and Self-abasement}

As per the household type, the student sources of city agricultural college can be divided into urban student source and rural student source, and their psychological characteristics after entering the school can present different degrees of selfesteem and self-abasement co-existence. As urban student source, when being compared with the same level of other rural student source, their economic conditions, horizons and mind can have unique advantages, and this has formed one side of self-esteem; however, after being enrolled in agricultural colleges, when being compared with the original high school classmates, they don't have outstanding performance and talents, so this has caused one side of self-abasement. As for rural students, if they are enrolled in colleges, this indicates that their learning capacity is outstanding, and the long-term "praises" can make them generate the "self-centered" psychological sense of superior; however, the family of origin fails to provide the relevant information about how to fit in urban life; from high school to college and from villages to cities, when being compared with urban student source, no matter it is the economic condition, living habits or thinking mode, they can have huge differences, and in the face of the huge difference between their dreams and the reality, they can feel self-abased due to admiring the superior conditions of urban student source on one hand; on the other hand, due to keeping the present status, they will show slight pathological self-esteem, and then more likely to be marginalized; if things continue this way, they will feel depressed, confused, anxious, and lack of confidence, and then finally show diffidence, the persistence in their old ways, cautiousness, over-cautiousness and other behavior characteristics [2]

\section{B. Behavior Characteristics}

\section{1) High Degree of Acceptance and Bad Endurance}

The generations "after 95s" are born in the era of fast developed science and technology, and the internet is a conventional technology that has accompanied them since their birth, and is quite familiar. Through the internet, the channel for them to obtain information is diversified, so in the face of the complicated information era, students can have an increasingly high degree of acceptance considering new things, but the endurance for certain things is increasingly worse[3]. According to the backstage data of certain public account provided by Tongbo LIU (the student representative of Mass Entrepreneurship Space in Tianjin Agricultural University), it is shows: within 4 months after "ai Xiaoyuanpai" is online, it has obtained above 4000 subscription volumes. However, according to another data provided by the institute, it is shows: when another public account--"Tianjin Agricultural University Campus Assistant" obtained more than 5000 subscription volumes within merely less than a week, and the flow is mainly from online small program games, red envelope and other interactive activities and higher quality tweets, and after the activity stops, users' activeness is also decreased accordingly.

\section{2) Fail to Adapt to College Life}

The excessive care of patents for their children has caused the lack of the basic living skills and the common sense of life of generation "after 95s"; this is mainly reflected in the phenomena of freshmen failing to fast adapt to college life after entering the school, being forgetful and causing many inconveniences: due to long-term easy life with everything provided, the generation "after $95 \mathrm{~s}$ " can be quite forgetful, and can often lose important certificates, etc. during the period of entering colleges from middle schools, without the reminding and monitoring of parents and teachers, which can be commonly seen; they may have disordered daily schedule, sharply decreased physical quality, and don't know where to see a doctor or how to take medicines even when they become ill; the relaxed and neglectful learning habits that lack in selfdiscipline can cause the frequent occurrence of failing exams; they lack in economic concept and prevention awareness, and with high worship for the money of some individuals, "net loan crisis", being caught in pyramid sales organizations and other problems can emerge in endlessly.

\section{3) Lack in Interpersonal Skills}

Along with the constant development of internet technologies, the popularization and alternation of various communication software's are happening all the time. People's communication and information exchange have become increasingly convenient, and both the time and space influence have become increasingly smaller, but there has also brought another problem: after getting used to virtual network communication mode, people's interaction capacity in actual life will be increasingly worse. As the main audiences for "Internet Plus", the generation "after 95s" is active in Microblog, WeChat, QQ, post bar, live and other kinds of network social contact platforms; they can talk freely, make friends, and chat a lot on the internet, but in daily life, they barely communicate with others, and don't even know about the contact information of their roommates. In this perspective, although the network has enriched students' channels to obtain information, it has also made them gradually lose the capacity to communicate with others in actual life; they will become shy and overcautious; meanwhile, the long-lasting academic pressure has also made most students show strong competitive awareness and vanity in daily life, and this has caused the failure in improving the interpersonal skills of students "after $95 \mathrm{~s} "[4]$

\section{CURRENT Status OF THE ProfESSIONAL ThOUGHTS OF FRESHMEN MAJORING AGRICULTURE}

\section{A. Relatively Low Professional Cognition Degree}

According to the investigation analysis of scholars about the freshmen of city agricultural universities and colleges in the recent years, at the end of the first semester, under the influence of many factors, such as non-first choice enrollment during the entrance, relatively few setup of professional courses, and the big difference between the life in agricultural colleges and their imaginations, freshmen of agricultural colleges, especially the freshmen "after 95s" can have a low cognition degree for the major learned by themselves, and most students don't understand about their professional connotation 
and leading-edge contents of what they learn, and even have no patients and interests in carefully understanding about professional knowledge, and will even make a fool of themselves by "realizing learning agriculture is equivalent to working as a farmer in the future".

\section{B. Strong Intension for Switching Major}

Since agricultural science and technology development is relatively backward when being compared with other leading science and technologies, agricultural college education reform can have hysteresis quality; objectively, agricultural major employment can include certain restrictions, toilsome works, low incomes and tremendous regional differences; besides, people have deep-rooted misunderstandings about traditional agricultures, and this has caused students' complicated psychology for learning agriculture, low interests in the specialty, the common phenomenon of "learning agriculture, but hating agriculture" as well as strong intention for switching major[5]. Although some students don't submit the application for switching major at the initial period after entrance, some students thereof select the their own majors with strong objectives, and all they want to do is to facilitate the transdisciplinary postgraduate examination or employment in the future.

\section{SUGGESTIONS AND COUNTERMEASURES}

\section{A. Use New Media to Conduct Well Professional Image Publicity Work}

Previously, students cannot have a deep and comprehensive understanding about the selected college and all the contents about the major via the text contents of the guidance manual, and the guidance and publicity effect is extremely limited. At present, the fast development of the internet has made people's life more convenient, and meanwhile, brought a new task. As a big characteristic for the group "after 95s", they dare to challenge new things and this has promoted their high cognition on the new media[6], and the main source for them to obtain information includes WeChat, Microblog, post bar, searching engine and other similar platforms. How to closely follow the new media development direction, actively utilize network platform to transmit professional information, and seek for the new approach for publicizing agricultural major images via new media interaction platform has become the new task for professional cognition education.

\section{B. Seize Key Period to Establish Solid Professional Feelings}

It is the key period for the freshmen about the conversion of living and learning mode when they enter the colleges; if series of rich, and diversified professional ideological education activities can be carried out among the freshmen group during this period, we can get twofold results with half the effort. Firstly, invite senior scholars and relevant enterprise technical personnel to carry out professional lecture, and then show the freshmen the industrial development frontier and stimulate learning impetus; secondly, carry out professional culture week activities, encourage all freshmen to participate in professional skill competition, professional knowledge competition and other series of themed activities, reinforce professional emotions of freshmen in activities and improve team spirits and innovation awareness in the process of material collection; besides, set practical activities about professional cognition, lead freshmen to visit the upstream and downstream enterprises and public institutions of the affiliated industry, to facilitate students to deepen their degree of identity for the major and help students establish professional confidence; finally, carry out experience communication conference, organize senior grades of excellent student representatives and excellent graduates to deliver speeches about their learning course, help freshmen build struggling objectives, reinforce their sense of pride for the major and then confirm and affirm professional feelings.

\section{Explore Teaching and Reform Scheme, and Gradually Replace Backward Teaching Mode}

Traditional teaching mode emphasizes on textbooks and teaching, students are under passive acceptance status, and the teaching effect for agricultural major that has strong practicalness is not good enough. Only when traditional course teaching has been gradually converted to open education, and more practical links are introduced as per professional characteristics can it help students convert from cramming learning to independent thinking and autonomous learning. Thus, the suggestion is that teaching shouldn't be restricted in classrooms, museums and the relevant units of the affiliated industries can also be regarded as the practical base for carrying out practical teaching. Meanwhile, innovative and comprehensive experiment design courses shall be carried out, and students can invite excellent teacher team and professional scientific workers as per their own task contents; with respect to the personnel composition structure, different grades are allowed to participate, and then form the team mode of "senior students leading freshmen", and then constantly reinforce the capacity of students to find and solve problems in practice, encourage students to obtain more participation degree in scientific research activities, reinforce professional sense of pride, affirm professional thoughts, stimulate learning impetus, promote it to deeply study professional knowledge and innovate professional development.

\section{Specific to Different Specialties, Carry out Professional Career Planning Courses as Soon as Possible}

As for the deep-rooted misunderstanding about "learning agriculture is equivalent to working as a farmer in the future", it derives from the fear for the unknown, and the cause thereof is the backward industrial information about traditional agricultural majors. When freshmen enter the college, they will face new living and learning mode; thus, the implementation of professional career planning course as soon as possible can help students improve their cognition degree and sense of identity for the major, deeply understand themselves and cultivate capacities. The course contents shall not be restricted by oral interpretation and text introduction, and it is requested to be extended to all learning and living aspects. For instance, organizing students to conduct employment character evaluation, learning to make personal resume, interview simulation college student entrepreneurship policy interpretation, college student innovation and entrepreneurship project and other relevant activities; in the process for students 
to collect materials and participate in activities, this can facilitate students to realize the industrial characteristics and advantages as soon as possible, cultivate sense of identity for the major, make an exclusive professional career plan as soon as possible in combination with the professional contents learned thereby, and seek for more specific struggling objectives.

\section{CONCLUSION}

After the 19th National Congress of the Communist Party of China, the "three-agriculture" problems have been promoted to a new height, and the construction of agricultural majors in colleges has become the emphasis for teaching reform, and the society has also increased its demand for agricultural major talents. The Ministry of Education has gradually enlarged the support strength for the construction of agricultural majors in agricultural colleges, and has also set special fund to encourage teachers to study the education and teaching reform. It is believed that, in the near future, with the constant endeavors of the governmental publicity department and the city agricultural colleges, the position of agricultural majors in the mind of examinees will be obviously improved.

\section{ACKNOWLEDGEMENT}

Fund program: Tianjin Agricultural University "Tianjin College Basic Scientific Research Business Expense Funding Project": Research about the Cognitive Education of Freshmen of Aquatic Majors under the Cultivation Background of Innovation and Entrepreneurship Talents (Task Approval No.: 2016JSYB02); Tianjin Agricultural College Teacher Education Reform and Innovation-led Development Project "Exploration about the Practical Teaching Scheme about the Innovation and
Entrepreneurship of Marine Fishery Science and Technology Specialty" (20170808);

About the author: Zhaojun TAN (1985-), female, Han nationality, the Teaching Secretary, Research Intern and Master of the Marine Production Institute of Tianjin Agricultural University; mainly engaged in teaching management work. E-mail: tanzhaojun1986@163.com

Corresponding author: Li LI (1981-), female, Han nationality, the Teaching Secretary, Assistant Researcher and Master of the Marine Production Institute of Tianjin Agricultural University; mainly engaged in teaching management work. E-mail: tjnxyshch@126.com.

\section{REFERENCES}

[1] Tianmu LIU. Exploration about the new Approach for the Entrance Education of Freshmen "after 95s"[J]. Higher Education Research and Practice, 2017,36(2): 64-68;

[2] Jinxia BAI, Pengpeng ZHANG, Haoli JIA, Investigation \& Analysis on Freshmen Characteristics of Agricultural Universities and Colleges and Reach on Educational Countermeasures [J]. Journal of Social Science of Shanxi Institution of Higher Education, 2017 (11): 93-96;

[3] Fangfang LI. Education Analysis on Freshman after "95" [J]. Journal of Social Science of Shanxi Institution of Higher Education, 2016, 28 (8):67-69.

[4] Xiaomeng ZHU. Reflection about the Education of College Freshmen "after 95s"[J]. Cultural and Educational Materials, 2015 (27): 140-141.

[5] Qinghui JIA, Yanying ZHANG, Yuqin LIU et al. Investigation about the Switch of Majors for Freshmen Majoring in Animal Medicine in Agricultural Colleges and the Countermeasures [J]. Animal Husbandry and Feed Science, 2013, 34 (2): 62-64.

[6] Junwei ZHAO, Canfei ZHANG. Discussion about the Entrance Education of Freshmen after 90s under the Background of Information Networking [J]. Reform and Opening-up, 2017 (4): 84-85. 